\title{
Sphenoid sinus pneumatization in a sample of Nepalese population: A multidetector computed tomography study.
}

\author{
Subita Lalchan ${ }^{1}$, Ashish Shrestha ${ }^{2}$, Bishnu Jwarchan ${ }^{3}$ \\ ${ }^{1}$ Assistant Professor, ${ }^{2}$ Resident, Department of Radiodiagnosis and Imaging, ${ }^{3}$ Assistant Professor, Department of $\backslash$ Medicine, \\ Manipal Teaching Hospital, Pokhara, Nepal.
}

Received: January 25, 2021

Accepted: February 28, 2021

Published: March 30, 2021

Cite this paper:

Lalchan S, Shrestha A, Jwarchan B. Sphenoid sinus pneumatization in a sample of Nepalese population: A multidetector computed tomography study. Journal of Brain and Spine Foundation Nepal. 2021:2(1):42-47.

\section{Correspondence:}

Subita Lalchan

Assistant Professor

Department of Radiodiagnosis and Imaging

Manipal Teaching Hospital, Pokhara, Nepal

Email: dr.subitajwarchan@gmail.com

ORCID: https://orcid.org/0000-0001-6509-6304.

\begin{abstract}
:
Introduction: The purpose of study was to assess the prevalence of different types of pneumatization of sphenoid sinus in the Nepalese population as detected in CT scan of paranasal sinus. Materials and Methods: This study included patients attending radiology department for CT scan of paranasal sinus. The CT images of paranasal sinus were assessed for the type of pneumatization of the sphenoid sinus and type of clival, lateral recess and lesser wing extensions. Results: Most common type of pneumatization found in our study was complete sellar type (61.7\%) and partial sellar type was second common type (27.4\%). Pre-sellar type of pneumatization was seen in $10.9 \%$. There were no patients with conchal type of pneumatization in our study. The clival extension of pneumatization was seen in 64\%, lateral extension was found in $35.4 \%$. and lesser wing type of pneumatization was found in 9.7\%. Conclusion: Pre-surgical assessment of types and extension of sphenoid sinus pneumatization helps surgeons in surgical planning and to reduce complications during surgery. The variation in prevalence of sphenoid sinus pneumatization was found between our study population and other different population. This confirms that ethnicity influences types and extension of sphenoid sinus pneumatization.
\end{abstract}

Keywords: Anatomic variation, Sella, Sphenoid sinus, Pneumatization.

\section{Introduction:}

The sphenoid bone is non-pneumatized at birth. CT scan can show pneumatization of the sphenoid sinus as early as two years of age. The sinus attains its adult size by the age of 14 years. ${ }^{1}$ There is great variation in degree of pneumatization of the sphenoid sinus. Pneumatization can be minimal to extensive. The pneumatization can extend into the greater wing of sphenoid, pterygoid process, clivus, and into the anterior clinoid process as well. The study of pneumatization patterns of sphenoid sinus has become very important due to newer developments in transsphenoidal endoscopic surgery for sellar and skull base lesions. Safe endoscopic endonasal transsphenoidal approach (EETA) depends on the anatomy of sphenoid sinus and skull base.

Conchal type of non-pneumatized sphenoid sinus is considered to be less favorable for trans-sphenoidal approach to the sella. ${ }^{2}$ Sellar type of pneumatization is important for trans-sphenoidal surgery of sellar lesion. Extended pneumatization of the sphenoid sinus is 
necessary for the extended transsphenoidal approach of para-sellar lesions.

The knowledge of variations of sphenoid sinus pneumatization helps surgeon in intraoperative guidance, predicting the complications of surgery and minimizing the complications during surgery. Hence, it is important to assess variations in pneumatization of sphenoid sinus. However, there is lack of study in the Nepalese population regarding variations in sphenoid sinus pneumatization. This study is done to identify the prevalence of various types of pneumatization of sphenoid sinus in our center which partly represents the broader picture of the Nepalese population.

\section{Methods:}

The Ethical committee approved this prospective crosssectional study. Patients attending department of radiology for CT PNS and CT head and face were included in the study. The study was done for period of four months; from September 2020 to December 2020. CT scan was performed with Philips Ingenuity 128 multislice scanner. Volume scans were obtained parallel to the orbitomeatal line. Reconstructed images in axial, coronal and sagittal planes were evaluated on Philips ISP (IntelliSpace Portal) workstation. CT images were assessed for types of pneumatization of sphenoid sinus; types of clival, lateral and lesser wing extension of pneumatization.

The sphenoid sinus was classified into conchal, presellar, incomplete sellar and complete sellar types as shown in figure 1 . The extension of pneumatization into the clivus was classified as shown in figure 2 . The lateral extension of pneumatization was classified as shown in figure 3 . The lesser wing pneumatization is said to be present when pneumatization is seen extending into either optic strut, lesser wing or anterior clinoid process (Figure 4).
Patients younger than 16 years, patient with facial trauma, sinonasal tumor, extensive rhinosinusitis and patient with history of surgery in paranasal sinus were excluded. Analysis was done using SPSS version 21.

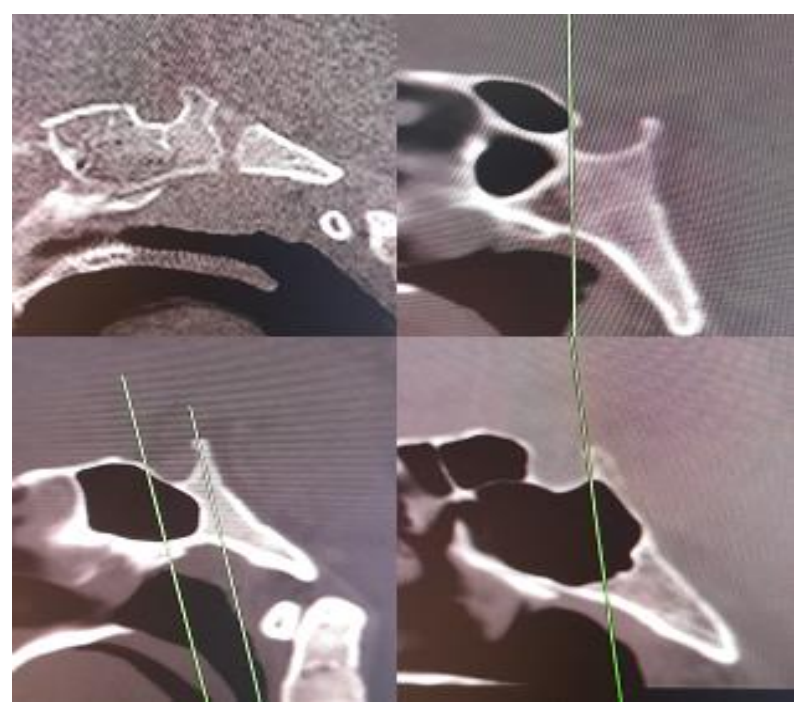

Figure 1: Vertical line is drawn along anterior and posterior wall of sella. Conchal type: Pneumatization > $10 \mathrm{~mm}$ anterior to anterior wall of sella. Presellar type: Posterior margin of pneumatization is anterior to the anterior wall. Incomplete sellar type: Posterior margin of pneumatization is beneath the sella but anterior to the posterior wall of sella. Complete sellar type: Posterior margin of pneumatization is posterior to the posterior wall of sella.

\section{Results:}

A total of 175 patients were assessed with CT, whose ages were ranging from 16 to 82 years with a mean of $40.59 \pm 18.058$. The study population comprised $49.7 \%$ females and $50.3 \%$ male patients.

\section{Sphenoid sinus pneumatization.}

Most common type of pneumatization noted in our study was complete sellar type, seen in 61.7\% (108). Partial sellar type was seen in $27.4 \%$ (48) and Pre-sellar type of pneumatization was seen in $10.9 \%$ (19). There were no patients with conchal type of sphenoid sinus in our study. There was no statistically significant difference in prevalence of pneumatization pattern between male and female (Table 1). 


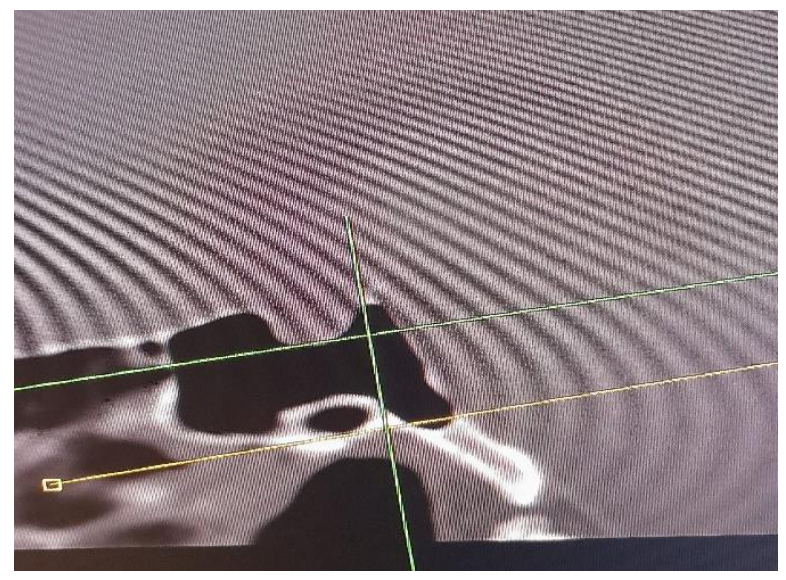

Figure 2: Types of clival extension: Horizontal lines are drawn at the inferior margin of sella and along the Vidian canal. Vertical line is drawn along the posterior wall of sella. Subdorsal type: Pneumatization is not extending above the line drawn at the inferior margin of sella and below the line drawn along the Vidian canal. Dorsal type: Pneumatization extending superiorly into the dorsum sella (above the line drawn along the inferior margin of sella). Occipital type: Pneumatization extending below the level of the Vidian canal. Combined: Dorsal + Occipital.

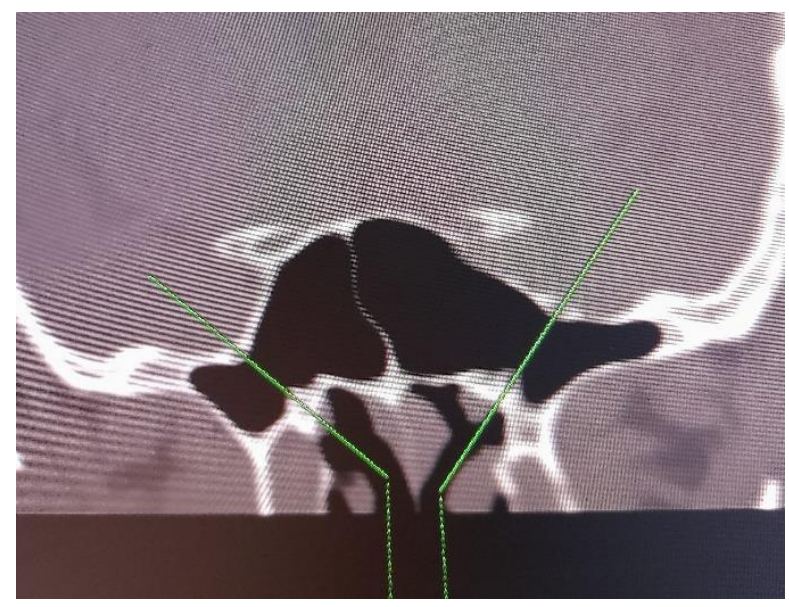

Figure 3: Lateral extension of pneumatization: Line is drawn along the medial margins of foramen rotundum and Vidian canal. Pterygoid: Pneumatization extending inferior to the Vidian canal into the pterygoid process. Greater wing of sphenoid: Pneumatization extending into greater wing of sphenoid beyond the foramen rotundum. Full lateral: Pterygoid and lateral.

\section{Clival Extension:}

The clival extension was seen in $64 \%$ of the patients. Among clival extension, the most common was the subdorsal type (55.4\%). Dorsal, occipital and combined type of clival extension was seen in $2.9 \%$ each. There was no statistically significant difference in prevalence of clival extension of pneumatization between male and female (Table 2).

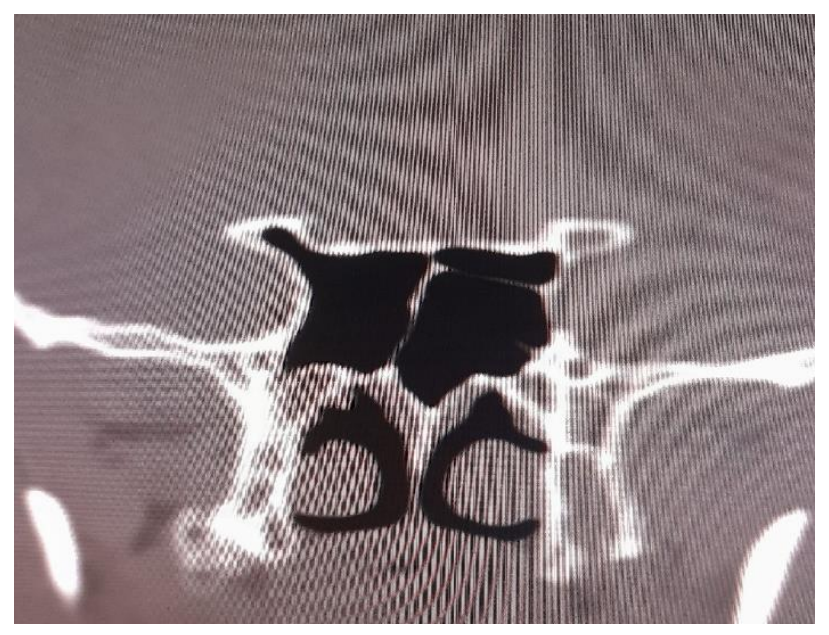

Figure 4: Lesser wing pneumatization

\section{Lateral extension:}

The lateral extension was found in $35.4 \%$. Pterygoid extension was seen in $9.7 \%$, greater wing extension was seen in $17.7 \%$ and full lateral extension was seen in $8 \%$. There was no statistically significant difference in prevalence of lateral extension of pneumatization between male and female (Table 3).

Table 1: Sphenoid sinus (SS) pneumatization according to sex.

\begin{tabular}{llll}
\hline SS & Male (\%) & Female (\%) & Total (\%) \\
$\begin{array}{l}\text { Pneumatization } \\
\text { Conchal }\end{array}$ & 0 & 0 & 0 \\
Presellar & $7(4)$ & $12(6.9)$ & $19(10.9)$ \\
Partial sellar & $25(14.3)$ & $23(13.1)$ & $48(27.4)$ \\
Complete sellar & $56(32)$ & $52(29.7)$ & $108(61.7)$ \\
\hline *P
\end{tabular}

\section{Lesser wing extension:}

Sphenoid sinus with lesser wing pneumatization had extension into either optic strut or anterior clinoid process. The lesser wing type of pneumatization was found in $9.7 \%$ of the sinuses. There was no statistically 
significant difference in prevalence of lesser wing extension between male and female (Table 4).

\begin{tabular}{|c|c|c|c|}
\hline $\begin{array}{l}\text { Clival } \\
\text { extension }\end{array}$ & Male $(\%)$ & Female $(\%)$ & Total (\%) \\
\hline Absent & $31(17.7)$ & $32(18.3)$ & $63(36)$ \\
\hline Sub-dorsal & $52(29.7)$ & $45(25.7)$ & $97(55.4)$ \\
\hline Dorsal & $1(0.6)$ & $4(2.3)$ & $5(2.9)$ \\
\hline Occipital & $3(1.7)$ & $2(1.1)$ & $5(2.9)$ \\
\hline Combined & $1(0.6)$ & $4(2.3)$ & $5(2.9)$ \\
\hline
\end{tabular}

Discussion:

Assessment of sphenoid sinus pneumatization is mandatory before surgery for sella and parasellar lesions. Sphenoid sinus was classified as conchal, presellar and sellar types by Hammer and Radberg. ${ }^{3}$ Later, sellar type was further divided into incomplete and complete types based on the extension of the pneumatization beyond the posterior wall of the sella. ${ }^{4}$ The pneumatization can extend into the greater wing of sphenoid, pterygoid process, clivus, and sometimes into the anterior clinoid process. Wang et al. ${ }^{5}$ further expanded the classification system to include the lateral and anterior extension to access possible sites in extended transsphenoidal sinus surgery.

Most common type of pneumatization found in our study was complete sellar type (61.7\%) and partial sellar type was second common type (27.4\%) as found in other studies. ${ }^{6,7}$

The least common type of sphenoid sinus in most studies was conchal type. It was found in $0.5 \%$ of cases in one of the study done in Turkish population. ${ }^{8}$ The overall prevalence of conchal type of pneumatization in previous studies was 1 to $2 \% .^{9-15}$ In one of the studies in Chinese population ${ }^{5}$; conchal type of pneumatization was found in $6 \%$. Conchal type of pneumatization was found in $4 \%$ on Caucasian cadavers. ${ }^{16}$

\begin{tabular}{llll}
\hline \multicolumn{4}{l}{ Table 3: Lateral extension. } \\
\hline $\begin{array}{l}\text { Lateral } \\
\text { extension }\end{array}$ & Male (\%) & Female (\%) & Total (\%) \\
Absent & $49(28)$ & $64(36.6)$ & $113(64.6)$ \\
Pterygoid & $11(6.3)$ & $6(3.4)$ & $17(9.7)$ \\
Greater wing & $18(10.3)$ & $13(7.4)$ & $31(17.7)$ \\
Full lateral & $10(5.7)$ & $4(3.2)$ & $14(8)$ \\
\hline *P value 0.077 & & &
\end{tabular}

However, there were no patients with conchal type of pneumatization in our study. Similar to our study; there were no patients with conchal type of pneumatization in several other studies. ${ }^{6,7}$

Pre-sellar type of pneumatization was seen in $10.9 \%$ in our study. Higher percentage of pre-sellar type of pneumatization was found in Chinese population $(28.5 \%)$ than our study. ${ }^{5}$

\begin{tabular}{llll}
\multicolumn{4}{l}{ Table 4: Lesser wing extension. } \\
\hline Lesser wing & Female (\%) & Male (\%) & Total (\%) \\
Absent & $83(47.4)$ & $75(42.9)$ & $158(90.3)$ \\
Present & $4(2.3)$ & $13(7.4)$ & $17(9.7)$ \\
\hline *P value 0.23 & & & \\
\hline
\end{tabular}

Significant difference was found in the prevalence of presellar type of pneumatization with overall prevalence ranging between 18.7 and 20.6\% in Caucasian and East Asian populations ${ }^{8-15}$ to $1.2 \%$ in Indian polupation. ${ }^{6}$ This finding shows that a lesser degree of pneumatization occurs in the Caucasian and East Asian populations than Indian population. Prevalence rate in our study was in between the Caucasian/East Asian population and Indian population. This finding could be due to mixture of Aryans and Mongolians in our study population. 
In our study, the clival extension was seen in $64 \%$, lateral extension was found in $35.4 \%$. and lesser wing type of pneumatization was found in $9.7 \%$. Among the lateral extension; pterygoid extension was seen in $9.7 \%$, greater wing extension was seen in $17.7 \%$ and full lateral extension was seen in $8 \%$. The prevalence of the lateral, clival and lesser wing extension in Chinese population was $11.4,21.4,0.8 \%$ of subjects, respectively ${ }^{5}$; which was less in comparison to our study population. In study done in Indian population ${ }^{6}$; the clival extension was seen in $76.6 \%$, lateral extension was found in $59.7 \%$ and the lesser wing type of pneumatization was found in $20.4 \%$ of the sinuses which was more in comparison to our study.

Endonasal transsphenoidal endoscopy has provided a safe and minimally invasive alternative to craniotomy for sellar and central skull base lesion. It is important to assess the variations of sphenoid sinus pneumatization to guide surgeons and prevent post-operative complications.

The Conchal type of sphenoid sinus is considered to be unfavorable for trans-sphenoidal surgery of sellar lesion and contraindication for extended trans-sphenoidal approach. Though hyper-pneumatization of sphenoid sinus is favorable for extended trans-sphenoidal surgeries for parasellar lesions; complications like injury of the vital structures and CSF leak is also high in cases of hyper-pneumatized sinus. Pre-operative identification of lateral extension type is very important to avoid injury to the carotid artery, maxillary nerve and vidian nerve. The lesser wing type of pneumatization can lead to the protrusion and thinning of bony wall of the optic nerve and internal carotid artery, predisposing them to injury during surgery.

Conclusions: This study evaluates the prevalence of different types of sphenoid sinus pneumatization and its extension. The sex of the patient had no relation to the pattern of sphenoid sinus pneumatization. The variation in prevalence of sphenoid sinus pneumatization among different population confirms that ethnicity influences the prevalence. Pre-surgical assessment of types and extension of sphenoid sinus pneumatization is important to aid surgeons in surgical planning and to reduce complications. Radiologists need to be aware of these variations and include them in routine reporting templates.

\section{Reference:}

1. Scuderi AJ, Harnsberger HR, Boyer RS. Pneumatization of the paranasal sinuses: normal features of importance to the accurate interpretation of CT scans and MR images. AJR Am J Roentgenol. 1993;160(5):1101-4. https://doi.org/10.2214/ajr.160.5.8470585.

2. Massoud AF, Powell M, Williams RA, Hindmarsh PC, Brook CG. Transsphenoidal surgery for pituitary tumours. Arch Dis Child. 1997;76(5):398-404. https://doi.org/10.1136/adc.76.5.398.

3. Hammer G, Radberg C. The sphenoidal sinus. An anatomical and roentgenologic study with reference to transsphenoid hypophysectomy. Acta Radiol. 1962;56:401-22. https://doi.org/10.1177/028418516105600601.

4. Güldner C, Pistorius SM, Diogo I, Bien S, Sesterhenn A, Werner JA. Analysis of pneumatization and neurovascular structures of the sphenoid sinus using cone-beam tomography (CBT). Acta Radiol. 2012;53(2):214-9. https://doi.org/10.1258/ar.2011.110381.

5. Lu Y, Pan J, Qi S, Shi J, Zhang X, Wu K. Pneumatization of the sphenoid sinus in Chinese: the differences from Caucasian and its application in the extended transsphenoidal approach. J Anat. 2011;219(2):132-42. https://doi.org/10.1111/j.14697580.2011.01380.x.

6. Hiremath SB, Gautam AA, Sheeja K, Benjamin G. Assessment of variations in sphenoid sinus 
pneumatization in Indian population: A multidetector computed tomography study. Indian J Radiol Imaging. 2018;28(3):273-9.

https://doi.org/10.4103/ijri.IJRI_70_18.

7. Dal Secchi MM, Dolci RLL, Teixeira R, Lazarini PR. An Analysis of Anatomic Variations of the Sphenoid Sinus and Its Relationship to the Internal Carotid Artery. Int Arch Otorhinolaryngol. 2018;22(2):161-6. https://doi.org/10.1055/s-0037-1607336.

8. Sevinc O, Is M, Barut C, Erdogan A. Anatomic Variations of Sphenoid Sinus Pneumatization in a Sample of Turkish Population: MRI Study. Int J Morphol. 2014;32:1140-3. https://doi.org/10.4067/S0717-95022014000400003

9. Wang J, Bidari S, Inoue K, Yang H, Rhoton A Jr. Extensions of the sphenoid sinus: a new classification. Neurosurgery. $\quad 2010 \quad$ Apr;66(4):797-816. https://doi.org/10.1227/01.NEU.0000367619.24800.B 1 .

10. Anusha B, Baharudin A, Philip R, Harvinder S, Shaffie BM, Ramiza RR. Anatomical variants of surgically important landmarks in the sphenoid sinus: a radiologic study in Southeast Asian patients. Surg Radiol Anat. 2015;37(10):1183-90. https://doi.org/10.1007/s00276015-1494-8.

11. Hamid O, El Fiky L, Hassan O, Kotb A, El Fiky S. Anatomic Variations of the Sphenoid Sinus and Their Impact on Trans-Sphenoid Pituitary Surgery. Skull Base. 2008;18(1):9-15. https://doi.org/10.1055/s-2007992764.

12. Lupascu M, Comsa GhI, Zainea V. Anatomical variations of the sphenoid sinus-a study of 200 cases. ARS Medica Tomitana. 2014;2:57-62. https://doi.org/10.2478/arsm-2014-0011.

13. Vaezi A, Cardenas E, Pinheiro-Neto C, Paluzzi A, Branstetter BF 4th, Gardner PA, Snyderman CH, et al. Classification of sphenoid sinus pneumatization: relevance for endoscopic skull base surgery. Laryngoscope. $2015 \quad$ Mar;125(3):577-81. https://doi.org/10.1002/lary.24989.

14. Li SL, Wang ZC, Xian JF. Study of variations in adult sphenoid sinus by multislice spiral computed tomography. Zhonghua Yi Xue Za Zhi. 2010 17;90(31):2172-6. Chinese. PMID: 21029655.

15. Lazaridis N, Natsis K, Koebke J, Themelis C. Nasal, sellar, and sphenoid sinus measurements in relation to pituitary surgery. Clin Anat. 2010;23(6):629-36. https://doi.org/10.1002/ca.20984.

16. Rahmati A, Ghafari R, AnjomShoa M. Normal Variations of Sphenoid Sinus and the Adjacent Structures Detected in Cone Beam Computed Tomography. J Dent (Shiraz). 2016;17(1):32-7. PMID: 26966706. 